\title{
A Copa do Mundo no Geogebra: em campo os Quadriláteros*
}

\section{Cássia de Souza Santos*** Rodrigo Nunes de Souza** José Carlos de Souza Júnior}

\author{
Universidade Federal de Alfenas (UNIFAL-MG) - Instituto de Ciências Exatas, \\ 37130-000, Alfenas, MG \\ E-mail: cassiaunifal@yahoo.com.br, rodrigonsouza19@gmail.com, jcsouzajr@uol.com.br
}

\begin{abstract}
RESUMO
Os Parâmetros Curriculares Nacionais [1] destacam a utilização dos recursos computacionais, por trazerem significativas contribuições que permitem aos alunos a construção de uma visão mais completa da verdadeira natureza da atividade matemática, e desenvolvendo atitudes positivas diante de seu estudo. Por outro lado, o uso destes recursos em sala de aula depende da escolha dos aplicativos, em função dos objetivos que se pretende atingir e da aprendizagem que orienta o processo.

Nascimento [2] afirma que "a utilização do software Geogebra como recurso didático no ensino da geometria, constitui um caminho que o professor pode seguir na perspectiva de chegar a uma maior satisfação em relação à aprendizagem".

Como este ano é de Copa do Mundo, a motivação foi englobar a Matemática a este evento mundial utilizando o Geogebra como recurso didático. O objetivo da atividade foi trabalhar no aluno o conceito dos quadriláteros de forma que os mesmos pudessem compará-los, compreendendo suas diferenças e reconhecendo suas propriedades. A atividade explora o campo de futebol e a formação tática de quatro seleções que participarão do mundial, cada formação tática esboça um quadrilátero envolvendo quatro jogadores, que previamente estava feito de acordo com as suas propriedades, conforme ilustrado na figura 1 .
\end{abstract}

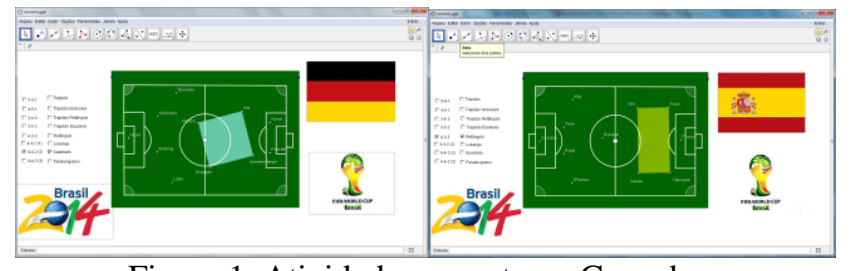

Figura 1. Atividade proposta no Geogebra.

A atividade foi aplicada em uma turma do sétimo ano do ensino fundamental de uma das escolas parceiras do Programa Institucional de Bolsas de Iniciação à Docência (PIBID). Os estudantes foram levados ao laboratório de informática da Universidade Federal de Alfenas (UNIFAL-MG), figura 2, para realizarem as atividades, uma vez que o laboratório de informática da escola não apresentava as condições de uso necessárias para o desenvolvimento da atividade.

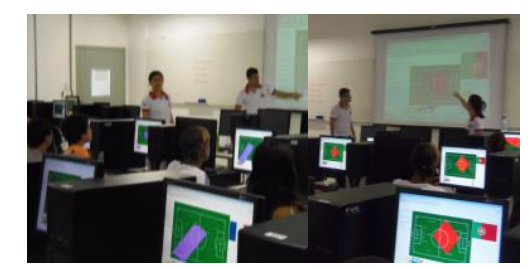

Figura 2. Alunos no laboratório desenvolvendo a atividade.

Durante a aula foi utilizado um caderno de acompanhamento e com o auxílio do Geogebra, o aluno tinha opção de escolher uma escalação e um quadrilátero, feito isso, deveria identificar o quadrilátero que na escalação poderia ser formado. Dessa forma, com as ferramentas do Geogebra foram analisados os ângulos, o paralelismo, a congruência e ângulos e os lados do quadrilátero, para que desse modo visualizassem as propriedades e particularidades do quadrilátero em questão.

* O presente trabalho foi realizado com apoio financeiro da Fundação de Amparo à Pesquisa do Estado de Minas Gerais (FAPEMIG) e do Programa Institucional de Bolsas de Iniciação à Docência (PIBID), da Coordenação de Aperfeiçoamento de Pessoal de Nível Superior (CAPES), Brasil.

** Bolsista de Iniciação à Docência. 
Ainda, na aula foi aplicado um questionário inicial (QI) e um questionário final (QF) para análise dos resultados, dos 21 alunos que participaram da atividade, 52,4\% efetivamente fizeram a atividade dos quais será relatado e comentado os resultados. As análises destes questionários basearam-se na forma de avaliação da escola, que requer $60 \%$ de rendimento nas disciplinas para aprovação.

Como a atividade envolve o futebol, esperava-se um desempenho melhor por parte dos meninos, uma vez que durante o acompanhamento das atividades do PIBID na turma evidenciou-se que as alunas eram mais envolvidas nas atividades, devido a isso e diante da demanda apresentada pela professora de matemática da turma, buscou-se desenvolver uma atividade que despertasse interesse nos meninos, houve interesse na atividade sobre o futebol, porém não fizeram efetivamente as atividades, o que evidencia que o tema não influencia somente o gênero masculino.

Foi verificado no QF o envolvimento dos alunos com o Geogebra e 79\% afirmaram positivamente que a atividade no Geogebra facilitou no aprendizado sobre os quadriláteros de forma dinâmica e contribuindo para o interesse pelo conteúdo, ressalta-se que essa foi a primeira vez que tiveram contato com este objeto de aprendizagem.

No gráfico da figura 3 são apresentados os resultados de 11 alunos que efetivamente fizeram a atividade até o final, visto que os demais não obtiveram o mesmo comprometimento. Observa-se que os alunos 1, 3, 4, 5 e 7 obtiveram no QI um aproveitamento abaixo de $60 \%$, conforme estabelecido pelo sistema de avaliação adotado pela escola. Mas, nota-se que ao final da atividade os mesmos atingiram no QF mais do que $60 \%$, evidenciando que a atividade contribuiu para que a aprendizagem do conteúdo dos quadriláteros. Ainda, os alunos 2 e 9 obtiveram a margem considerável e a manteve, já com os alunos 6,8 e 10 ocorreu o mesmo, mas conseguiram avançar a mais da margem considerada.

Durante a atividade, observou-se que com o objeto de aprendizagem e a forma na qual foi proposto, os alunos tiveram a oportunidade de comparar os quadriláteros, e com as ferramentas puderam manuseá-los e visualizarem que um mesmo quadrilátero pode ser outro ao mesmo tempo, como por exemplo, o quadrado pode ser um retângulo, pois tem as propriedades de retângulo. Além disso, constataram que o inverso não pode ocorrer.

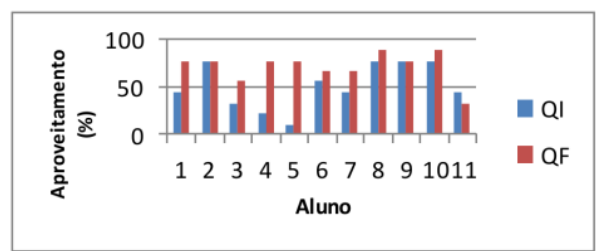

Figura 3. Gráfico sobre o aproveitamento de 11 alunos no QI e QF.

Essa atividade serviu como uma complementação do conteúdo visto em sala de aula, e os resultados foram satisfatórios, pois consolidou este conteúdo e ao mesmo tempo prendeu a atenção dos alunos, uma vez que eles acompanharam e fizeram as atividades, mostrando uma evolução no domínio do conteúdo. Essa atividade pode ser aplicada tanto para rever, quanto para ensinar as propriedades e definições dos quadriláteros. Além disso, constatou-se que é possível utilizar objetos de aprendizagem nas aulas de matemática, porém há barreiras para serem utilizados com relação ao uso desses objetos na escola devido à estrutura dos laboratórios das escolas públicas.

Palavras-chave: Ensino de Matemática, Geometria dinâmica, Objeto de Aprendizagem.

\section{Referências}

[1] Brasil. (1998) Parâmetros Curriculares Nacionais para o Ensino Fundamental. Brasília.

[2] E. D. A. Nascimento, "Coletânea LABGG para Escolas e Universidades: Nf2.901 Possibilidades de Estudo para a Função Quadrática", GeoGebra Uruguay, pp. 141-148, Actas de La Conferencia Latinoamericana de Geogebra, Uruguai, 2012. 